\title{
Final Technical Report:
}

\section{Summary of Work Completed under DOE Grant DE-SC0005513}

The main goal of this project funded through this DOE grant is to help in the establishment of the University of Delaware Energy Institute (UDEI) which is designed to be a long-term, ongoing project. The broad mission of UDEI is to develop collaborative programs encouraging research activities in the new and emerging energy technologies and to partner with industry and government in meeting the challenges posed by the nation's pressing energy needs.

\section{Research-related Activities Completed:}

The research component of this project involved a number of activities including:

1) awarding student fellowships in cross-disciplinary energy-related areas. A number of students were funded mainly during the first year of this grant. These students worked in areas such as:

- modeling the kinetics of the conversion of biomass to bio-oils and fuels

- modeling the structure and properties of biomass feedstocks used in the production of bio-oils and fuels.

- research on hydrogen production from water electrolysis

- investigating the direct conversion of biomass to hydrogen using photoelectrochemical devices

- studying novel catalytic materials for low temperature fuel cells

- exploring the utilization of carbides as low cost electrocatalysts for fuel cells

In addition, students were provided opportunities to help set up and upgrade the facilities in the UDEI laboratories for energy research.

2) educational outreach initiatives - the UDEI Annual Symposia were held on March 10, 2011 and June 6, 2012 with over 100 attendees at each event. These day-long conferences were designed to showcase UD energy-related activities and to heighten awareness of potential collaborative opportunities which could be initiated and advanced by the UDEI. They featured presentations by cutting-edge UD researchers in the energy field as well as presentations from outside the university providing an industry perspective on energy issues. Student poster sessions also played an important role at the conferences. The audience at these conferences included students, faculty, and researchers, government policymakers, industry representatives, non-profit organizations and the general public.

3) programmatic expenses - expenses included partial support for the Assistant Director of UDEI and for administrative assistant support as well as purchase of basic office supplies for the operation of the Institute. 


\section{Capital Equipment and Laboratory Construction:}

Another major component of this project involved the investment in laboratory facilities dedicated to UDEI. Through this grant, we established a UDEI research laboratory facility with a suite of characterization techniques. These shared facilities have been made available to research groups at the University of Delaware to perform energy-related research. The main techniques include:

$X$-Ray Photoelectron Spectroscopy (XPS): An XPS system was assembled using parts from the laboratories of several UD faculty members. The DOE funding was used to purchase missing pieces, including an X-ray source and cooling system, a turbo pump and mechanical pumps. The XPS system is operational and is a useful tool to determine the surface elemental composition of materials and catalysts.

$X$-ray Diffraction (XRD): An XRD system was donated by a faculty member to UDEI. The DOE funding was used to upgrade the $X$-ray source and data acquisition system. The XRD system is operational and is a useful tool to determine the bulk structures of materials and catalysts.

Inductive Coupled Plasma (ICP): The inductively coupled plasma optical emission spectrometer (ICP-OES) equipment itself was donated by a faculty member to UDEI. The DOE Funding was used to upgrade the data acquisition system. The ICP was installed in the UDEI laboratories and a complete refurbishment of the system was carried out including the data acquisition system. This was completed in the spring of 2011 with the unit in working order. This equipment provides quantification of elemental compositions in both bulk materials and supported catalysts. To date, the spectrometer has been employed for mainly photovoltaics-related projects. There have, however, been a number of maintenance issues with this unit, resulting in significant downtime. These issues are currently under review for repair.

BET Physisorption: The DOE funding was used to purchase a BET Physisorption equipment, which can be used to measure the surface area and pore size distribution of materials for energy applications. The instrument is operational.

Fuel Cell Test Station: The DOE funding was used to purchase a fuel cell test station to evaluate electrochemical performance of polymer electrode membrane (PEM) fuel cells. The system is operational and is currently being maintained by a UD research group, which provides assistance to other UD research groups for electrochemical studies.

Battery Test Station: The DOE funding was used to purchase a batter test station to evaluate the charging and discharging of battery materials for energy storage. The system is operational and is currently being maintained by a UD research group, which provides assistance to other UD research groups interested in battery research. 
Currently, the UDEI research laboratory facility consists of three laboratories of approximately $1,500 \mathrm{sq}$. ft. The laboratories were upgraded, with utilities, such as cooling water and power, matching the needs of the characterization techniques. The DOE funding through this grant was used to partially support the laboratory upgrade and renovation.

\section{General Status Report:}

The University of Delaware Energy Institute is a long-term, on-going project. Its overall purpose of developing a collaborative and integrative program in new and emerging energy technologies involves a number of critical missions. Specific milestones would entail the attainment of these objectives which will be achieved over a period of time. These include:

1) Development and deployment of new alternative energy technologies

2) Development of UDEI as a primary resource for public and private sector decision makers in the State and region

3) Creation of strong partnerships amongst research, education, and operations at UD and externally with industry and the public sector

4) Competitiveness of Delaware researchers for new contracts and grants for collaborative research in the energy field

5) Consciousness on campus and in the local and state communities regarding energy sustainability issues.

With the successful completion of the UDEI's Annual Symposia, we are well on our way to developing collaborative research activities in the research field both within the university and with outside partners. The Symposia also raised the consciousness of sustainability activities on campus and in the wider community. The upgrading of UDEI laboratory facilities has enabled us to be an important resource for the development and expansion of energy-related research at the University of Delaware and in the broader scientific community. 